\title{
КОЛЕСНАЯ БРОНЕВАЯ ТЕХНИКА КРАСНОЙ АРМИИ В ВЕЛИКОЙ ОТЕЧЕСТВЕННОЙ ВОЙНЕ
}

\section{WHEELED ARMORED VEHICLES OF THE RED ARMY IN THE GREAT PATRIOTIC WAR}

M. Tosheva

N. Tosheva

Summary: Object: to consider the features of the formation of the armored fleet of the Red Army in the field of its provision with armored vehicles of the middle class and their use in severe and dramatic conditions of the initial period of the Great Patriotic War.

Methods: comparative-analytical, chronological, statistical. Findings: the specifics of equipping the Soviet troops with armored vehicles in the chronological period under consideration are revealed. Conclusions: objective and subjective conditions prevailing in the initial period of the war, as well as the specifics of the manufacture, maintenance, repair and operation of armored vehicles determined the policy of the Soviet state in the field of their use in the formation of the Red Army fleet.

Keywords: The USSR, the Great Patriotic War, the Red Army, wheeled armored vehicles, armored cars. тошева Милена Стефановна

К.и.н., доцент, Старооскольский филиал ФГБОУ ВО «Российский государственный геологоразведочный университет имени Серго Орджоникидзе» sofmgri-gdeip@yandex.ru

Тошева Наталья Александровна

к.ф.н., доцент, Старооскольский филиал ФГБОУ ВО «Российский государственный геологоразведочный университет имени Серго Орджоникидзе»

Аннотация: Цель: рассмотреть особенности формирования броневого парка РККА в сфере его обеспечения бронированными автомобилями среднего класса и их использования в тяжелых и драматичных условиях начального периода ВОВ.

Методы: сравнительно-аналитический, хронологический, статистический. Результаты: выявлена специфика оснащения советских войск броневыми автомобилями в рассматриваемый хронологический период.

Выводы: объективные и субъективные условия, сложившиеся в начальный период войны, а также особенности изготовления, обслуживания, ремонта и возможностей эксплуатации бронемашин детерминировали политику Советского государства в сфере использования их в формировании автопарка PKKA.

Ключевые слова: СССР, Великая Отечественная война, Красная Армия, колесная бронетехника, бронеавтомобили.

рые особенности формирования броневого парка РККА в сфере его обеспечения бронированными автомобилями среднего класса и их использования в тяжелых и драматичных условиях начального периода Великой Отечественной войны.

В России броневые автомобили появились осенью 1914 г. и сразу стали использоваться в боях во время Первой Мировой войны. Уже в этот период Русская армия имела несколько сотен различных броневиков. Часть из них изготавливалась на отечественных предприятиях, а часть заказывалась по русским проектам в Англии. К 1917 г. броневое дело в России, как по качеству машин, так и по тактике их боевого применения было поставлено намного лучше, чем во всех остальных воюющих странах.

Большевики, пришедшие к власти в октябре 1917 г., прекрасно понимали, какую роль для обороноспособности страны играет техническое обеспечение красной Армии, в том числе колесной броневой техникой. Тридцать первого января 1918 г. Совет Народных Комиссаров РСФСР издал распоряжение о создании Центрального совета броневых частей (Центробронь), которому поручалось оперативно начать работу по учету оставшегося от царской армии броневого имущества и формирова-

В данной статье мы хотели бы рассмотреть некото- 
нию броневых частей [См.: 1, с. 5].

С марта 1918 г. броневые машины начинают использоваться Красной Армией на фронтах Гражданской войны, чаще всего в составе броневых отрядов. Тринадцатого ноября 1918 г. Революционный военный совет РСФСР утвердил штат автобронеотряда: 4 бронемашины, 12 автомобилей (грузовые, легковые, специальные), 4 мотоцикла [См.: 2, с. 143-144].

После окончания Гражданской войны количество броневиков сократилось: машины были сильно изношены, а отсутствие запчастей затрудняло ремонт.

Только с появлением собственной автомобильной промышленности в СССР и началом производства полуторатонного АМО-Ф-15 возобновились работы по проектированию и изготовлению новых моделей броневых автомобилей уже на шасси этого грузовика. Главным разработчиком и изготовителем стал Ижорский завод, расположенный в г. Колпино Ленинградской области. Сборку первого броневика под индексом БА-27 закончили в марте 1928 г. и после испытаний началось его серийное производство. Всего за 1928-1931 гг. было выпущено 215 экземпляров БА-27 [См.: 1, с. 24].

К началу 1930-х гг. более или менее перспективными специалисты того времени считали три модели: Д-13 конструкции Дыренкова на шасси «Ford-AAA», ФВВ разработки Авто-танко-тракторного бюро экономического управления ОГПУ (АТТБ ЭКУ ОГПУ) на шасси «Ford Timken» и БАИ (Броневой автомобиль Ижорского завода) также на шасси «Timken». У всех этих моделей имелись как позитивные черты, так и общие недостатки. К последним относили:

- то, что все они базировались на шасси иностранных моделей, что затрудняло крупносерийное производство;

- перегрев радиатора и как следствие повышение температуры внутри машины при движении с закрытыми люками. Это негативно сказывалось на здоровье и работоспособности экипажа;

- довольно слабое вооружение: пушка Гочкис (37 мм) и 1 пулемет ДТ (7,62 мм).

Вместе с тем, модель БАИ оказалась более компактной по сравнению с другими и при испытаниях показала неплохие динамические качества. Удовлетворительными комиссия посчитала и результаты стрельб, и проходимость.

Для эксплуатации машину признали пригодной, но для приема как боевой «... у нее необходимо прекратить доступ горячего воздуха от мотора к водителю...» [См.: 3, Д. 285. Л. 1-120].

Поэтому данная модель была выбрана как основной тип среднего бронеавтомобиля для валового производства на конец 1932 г. и на 1933 г. при условии минимизации обнаруженных недостатков.

Конструкторы Ижорского завода внесли следующие изменения: предусмотрели два окна (по одному на каждую сторону) в бортах моторного отсека для выброса горячего воздуха, поставили дополнительные лючки для вытяжного вентилятора. Вооружение усилили, установив более мощную пушку (калибра 45 мм) и два пулемета ДТ (7,62 мм). Один из них находился в штатной башенной установке, а другой - в лобовом листе корпуса. Кроме этого, сделали три отверстия с броневыми заслонками для стрельбы из револьвера.

Машина под индексом БА-3 начала выпускаться на Ижорском заводе с 1934 г. Всего завод изготовил 168 экземпляров. В 1936 г. данную модель модернизировали и под маркой БА-б запустили в серийное производство [См.: 1, с. 53].

В 1932 г. вступило в строй новое предприятие - Горьковский автомобильный завод, и выпускаемые им грузовики вполне могли использоваться в качестве шасси для новых моделей бронированных автомобилей.

Таким образом, в первой половине 1930-х гг. ускоренными темпами формировалась производственная база для изготовления колесных бронемашин, позволившая с 1935 г. по 1941 г. создать довольно широкую линейку броневиков среднего класса на шасси уже отечественных автомобилей, в частности, на укороченном шасси трехосного ГАЗ-ААА. Ими стали БА-6, БА-6М, БА-10/БА10А, БА-10М. Это были машины полностью советского производства.

Модель БА-6 представляла собой модернизированный БА-3. Смысл модернизации заключался в следующем:

1. Корпус и башня от БА-З практически без изменений были переставлены на более легкое укороченное серийное шасси ГАЗ-ААА, позволившее уменьшить боевую массу БА-6 на 700 кг (5120 кг у БА-6 против 5820 кг у БА-3). К тому же, у ГАЗ-ААА колея была шире, чем у импортных шасси Ford Timken, что повышало устойчивость броневика при движении по пересеченной местности и на крутых поворотах [См.: 4, с. 88-89].

2. На БА-6 были впервые применены пулестойкие шины ГК («губчатая камера») с наполнителем из губчатой резины вместо пневматических шин, уязвимых для пуль и проколов [См.: 4, с. 88-89].

3. Для повышения интенсивности охлаждения добавлен еще один небольшой люк над моторным отделением.

4. Появилось внутреннее освещение.

5. Значительно возросло количество и ассортимент 
запасных инструментов и деталей.

Кроме этого, было усилено крепление корпуса к шасси, уменьшен угол наклона рулевой колонки, увеличена емкость бензобаков.

Производство БА-6 продолжалось на Ижорском заводе до 1938 г. Всего было изготовлено 394 бронеавтомобиля [См.: 5, с. 175].

В 1936-1937 гг. в дополнение к БА-б был создан облегченный и более компактный вариант - БА-6М.

В таблице 1 представлены некоторые характеристики бронемашин среднего класса, имевшихся в распоряжении Красной Армии к 1941 г.

Анализ таблицы позволяет выявить следующие отличия:

1. За счет сокращения длины шасси и установки новой более легкой конической башни удалось уменьшить боевую массу БА-6М по сравнению с БА-6 на 320 кг, а броню усилить до 10 мм. К тому же, из-за изменения углов наклона такой тип башни имел лучшую пулеустойчивость.

2. Мощность БА-6М увеличилась до 50 л.с., а скорость - до $52 \mathrm{KM} / 4$.

3. Появился дополнительный топливный бак на 52 л бензина.

Все машины снабжались радиостанциями. До конца 1938 г. Ижорский завод изготовил 386 экземпляров [См.: 7, с. 51]. Часть машин БА-6 и БА-6М участвовала в конфликтах на пограничных территориях СССР в конце 1930-х гг. Оставшаяся часть использовалась в боевых действиях в начальный период Великой Отечественной войны. Доработанный БА-6М послужил прототипом серийного бронеавтомобиля БА-10/БА-10А. Последний оказался наиболее распространенным и известным пушечным бронеавтомобилем среднего класса. В нем были объединены все конструктивные достоинства, опыт испытаний и эксплуатации колесных броневых машин прежних моделей.

Основой БА-10 так же, как и у БА-6М, стало короткобазное шасси ГАЗ-ААА. Одинаковыми у этих моделей остались: корпус из катаной стали с толщиной брони от 2,5-4 мм (днище) до 10 мм (корпус); конический тип башни; вооружение: пушка 45 мм и два пулемета ДТ 7,62 мм.

Вместе с тем, имелись и отличия: существенно возросла емкость баков (118 л БА-10 против 96 л БА-6М); запас хода увеличился на 50 км.

По качественным характеристикам в модификации БА-10 была усилена балка переднего моста и попере-

Таблица 1.

Тактико-технические характеристики бронеавтомобилей среднего класса, состоявших на вооружении в РККА к началу Великой Отечественной войны [Сост. автором по: 1: с. 58-61, 92-95, 102; 5: с. 175-176, 178-179; 6, с. 373-376].

\begin{tabular}{|c|c|c|c|c|}
\hline Характеристики & БА-6 & БА-6M & $\begin{array}{l}5 \mathrm{~L}-10 / \\
\text { БА-10A } \\
\end{array}$ & БА-10М \\
\hline 1 & 2 & 3 & 4 & 5 \\
\hline Длина (мм) & 4900 & 4655 & 4450 & 4450 \\
\hline Ширина (мм) & 2070 & 2300 & 2100 & 2100 \\
\hline Высота (мм) & 2360 & 2150 & 2155 & 2470 \\
\hline Боевая масса (кг) & 5120 & 4800 & 5120 & 5360 \\
\hline Мощность (л.с.) & 40 & 50 & 50 & 50 \\
\hline Скорость по шоссе (км/ч) & 42 & 52 & 53 & 53 \\
\hline Запас хода по шоссе (км) & 265 & 250 & До 300 & $285-300$ \\
\hline Тип башни & Цилиндрическая & Коническая & Коническая & Коническая \\
\hline $\begin{array}{l}\text { Бензобаки (емкость, л): } \\
\text { - основной } \\
\text { - дополнительный }\end{array}$ & $\begin{array}{l}44 \\
24 \\
\end{array}$ & $\begin{array}{l}44 \\
52 \\
\end{array}$ & $\begin{array}{l}59 \\
59\end{array}$ & $\begin{array}{l}54,5 \\
54,5 \\
\end{array}$ \\
\hline $\begin{array}{l}\text { Бронирование (толщина, мм): } \\
\text { - лобовой лист корпуса } \\
\text { - борта корпуса } \\
\text { - корма корпуса } \\
\text { - крыша } \\
\text { - днище }\end{array}$ & $\begin{array}{c}8-9 \\
8 \\
8 \\
4 \\
3 \\
\end{array}$ & $\begin{array}{c}10 \\
10 \\
9 \\
4 \\
2,5 \\
\end{array}$ & $\begin{array}{c}10 \\
10 \\
10 \\
6 \\
4 \\
\end{array}$ & $\begin{array}{c}10 \\
10 \\
10 \\
6 \\
4 \\
\end{array}$ \\
\hline
\end{tabular}


чины рамы; улучшена за счет дополнительного люка система вентиляции и охлаждения моторного отсека. Из двух пулеметов один был спарен с пушкой, а второй располагался на лобовом листе корпуса рядом с водителем на специальной выштамповке, позволявшей вынести орудие вперед. Тем самым создавались более удобные условия для ведения огня.

Броневик снабжался большим по количеству и ассортименту шанцевым и автомобильным инструментом. Имелся дополнительный комплект внутреннего оборудования и противоскользящие цепи «Overoll» [Cм.: 1, с. 98-102; 7, с. 52-53]. Вся электрика убиралась в бронированные шланги.

В отличие от БА-6М, люки и двери БА-10 имели «отбортовки» для защиты от попадания внутрь свинцовых брызг при обстреле. Было внесено еще довольно большое количество мелких изменений, на каждое из которых требовалось разработать технологическую документацию для производства.

После внесения всех изменений и оформления соответствующей документации машину с января 1938 г. стали выпускать под индексом БА-10А.

Наряду с положительными качествами в процессе эксплуатации обнаружились и недостатки:

1. В зимних условиях резина ГК выходила из строя через 1000-1100 км, если броневик постоянно находился в движении.

2. Не очень удачным оказалось расположение бензобаков внутри машины. С одной стороны, был велик риск взрыва или пожара при попадании в них пуль или снарядов при обстреле. С другой стороны, водителю сложно взаимодействовать с боевым отсеком. Необходимо было переместить баки наружу и дополнительно защитить их броней.

3. В довольно низком рулевом отсеке комфортно было водителям с ростом не выше 170 см. Иначе голова почти касалась потолка, что повышало травмоопасность при движении по тряским дорогам. К тому же, жесткие сиденья провоцировали у водителей боли в позвоночнике.

4. Не удалось до конца ликвидировать проблему повышения температуры воздуха в кабине при движении с закрытыми люками (т.е. в боевом положении) [См.: 1, с. 107-109; 3, Д. 1054. Л. 1-94, Д. 1056. Л. 1-78, Д. 2100. Л. 1-22].

В конце 1939 г. в конструкцию БА-10А внесли ряд изменений. Модернизированный бронеавтомобиль, получивший обозначение БА-10М, отличался от предшественников повышенной защищенностью экипажа и оборудования. Она выразилась в следующем:

1. Прежде всего, машина получила топливные баки новой конструкции, которые устанавливались на крыльях задних колес и защищались бронированными кожухами.

2. Бензопроводы убрали под днище машины и прикрыли броневыми планками.

3. Пулеметную установку в лобовом листе также защитили бронированными элементами.

4. Более рационально разместили снаряжение и оборудование внутри корпуса: усовершенствовали расположение и качество сидений, убрали под пол ящик для инструментов, изменили крепления аптечки и ракетницы, установили сумку для ручных гранат.

5. Появился новый механизм поворота башни.

Все это позволило снизить пожароопасность броневика, обеспечить защиту экипажа от горящего бензина при повреждении бензобаков и таким образом повысить эффективность действий бойцов.

С 1938 г. по сентябрь 1941 г. ижорский завод передал на вооружение Красной Армии 3392 бронемашины БА10; за тот же период был произведен 3331 автомобиль БА-10А и БА-10М [См.: 1, с. 116-117].

К началу Великой Отечественной войны, согласно сведениям о наличии колесной бронетехники в РККА на 1 июня 1941 г., бронеавтомобилей среднего класса имелось 3345. Из них 3077 (92\%) были вооружены пушками 45 мм. Из последних 2462 (80\%) представляли модели БА-10/БА-10А.

С началом военных действий часть бронемашин была уничтожена в результате авианалетов вермахта. Особенно большие потери в этом плане понесли войска Западного Особого военного округа (ЗапОВО).

Использование бронемашин в военных условиях имело свои особенности, которые, к сожалению, удалось выявить не сразу.

Так, в первые месяцы войны их часто применяли для поддержки атак пехоты непосредственно на полнее боя. Это оказалось малоэффективно и приводило к неоправданно большим потерям.

Выполнение же броневиками разведывательных задач было успешным. Вот один из примеров. 22 июня 1941 г. взводу бронемашины лейтенанта Суровцева 5-й танковой дивизии 3-го механизированного корпуса командование дало задание провести разведку. При подходе к указанному району Суровцев организовал засаду в лесу по обе стороны от шоссе. Машины замаскировали так, что их трудно было заметить уже с расстояния 200300 м. Когда появился взвод мотоциклистов, их уничтожили. Через 40 минут появились три танка, которые были подожжены первыми же выстрелами. Еще через 10 минут подошла колонна из 15 танков в сопровождении 
мотоциклистов. БА-10 вывели из строя своим огнем еще три танка и более двух десятков мотоциклов и вынудили немцев повернуть обратно.

Таким образом, грамотно организованная засада дала результат: 6 бронемашин подбили и уничтожили 6 танков и несколько десятков мотоциклов [См.: 1, с. 300].

В первый период Великой Отечественной войны колесная броневая техника среднего класса применялась на многих фронтах, но наибольшее распространение получила на Ленинградском фронте. Ее успешное использование было связано со следующими обстоятельствами.

Во-первых, под Ленинградом находилось единственное в стране предприятие по выпуску бронеавтомобилей БА-10 и их модификаций - Ижорский завод. С октября 1941 г. его мощности были переведены на Ленинградский завод № 189, но производство не останавливалось, завод мог снабжать формировавшиеся здесь войска техникой непосредственно из цехов. К тому же Ленинград, как крупный промышленный центр, имел возможность осуществлять качественный ремонт поврежденной бронетехники.

Во-вторых, после окружения города, военные действия здесь стали носить позиционный характер, и боевое применение бронеавтомобилей в качестве подвижных засад, для разведки, связи, охраны колонн оказалось эффективным. Для этого по решению Военного совета Ленинградского фронта началось формирование самостоятельных частей - отдельных автоброневых батальонов (ОАББ). По штату такой батальон состоял из двух рот, взвода обеспечения, управления и штаба. Всего: 20 бронемашин, 8 грузовиков, ремонтная летучка типа А, бензозаправщик. Личный состав - 114 человек.

Первый батальон такого типа (1-й ОАББ) сначала вошел в состав 2-го оборонительного района, а позже совместно с 389-й стрелковой дивизией вё л оборону западного побережья Ладожского озера [См.: 1, с. 310]. Автобронебатальон участвовал в боях практически до весны 1944 г. Летом 1942 г. был сформирован 2-й ОАББ. Оба батальона использовались для усиления обороны стрелковых частей, как подвижный резерв и для решения разведывательных задач. Расформированы они были лишь весной 1946 г. Следует отметить, что и на других участках Ленинградского фронта в 1944-1945 гг. еще применялись броневые автомобили. Например, в 152-й танковой бригаде, в 54-й армии и других.

\section{В заключение можно сделать следующие выводы.}

Колесная бронетехника являлась необходимым элементом вооруженных сил, как в дореволюционной русской армии, так и в РККА. К особенностям формирования броневого автопарка в Красной Армии следует, вопервых, отнести то, что бронемашины изготавливались на базе обычных серийных грузовиков, только укороченной. Никаких специальных шасси для броневиков в стране не производилось. Переделки стандартного шасси обходились дешевле. К тому же, машины было легче обслуживать и ремонтировать.

Во-вторых, кузов автомобиля мог изготавливаться отдельно от шасси и заблаговременно, что позволяло, при необходимости, корректировать планы выпуска.

B-третьих, опыт боевого применения пушечных бронеавтомобилей среднего класса в начальном периоде Великой Отечественной войны показал, что их нельзя было использовать «по-танковому» - для поддержки атак пехоты или атаки укреплений противника непосредственно на поле боя. Ведь защита у них была только противопульная, а по проходимости они уступали гусеничной технике. А вот в обороне, разведке, связи и сопровождении колонн их действия были вполне успешными.

Выполнение этих функций броневые автомобили осуществляли практически до конца войны.

\section{ЛИТЕРАТУРА}

1. Коломиец, М.В. Бронемашины Сталина 1925-1945. - М.: Яуза: Эксмо, 2010. - 384 с.: ил.

2. РСФСР. Революционный военный совет. Приказы Революционного военного совета Республики . . [по годам]. - [М., 1918-1919]. - № 220. - 1918. - 176 с.

3. Российский государственный военный архив (РГВА). Ф. 31811. 0п. 2.

4. Исмагилов Р. Бронетехника XX века: танки, САУ, военные машины / Р. Исмагилов, Г. Корнюхин, Д. Марченко, Б. Проказов. - Смоленск: Русич, 2006. - 560 с.: ил.

5. Кочнев Е.Д. Автомобили Красной Армии 1918-1945. - М.: Яуза: Эксмо, 2009. - 544 с.

6. Коломиец М.В. Броня на колесах. История советского бронеавтомобиля 1923-1945 гг. - М.: Яуза, Стратегия КМ, Эксмо, 2007. - 384 с.

7. Газенко В.Н. Бронетранспортеры и бронемашины России: Иллюстрированный справочник / В.Н. Газенко, В.Е Ильин. - М.: 000 «Издательство Астрель»; 000 «Издательство АСТ», 2001. - 128 с.: ил. 